\title{
Commentary: Minding the gaps
}

\author{
Dawn S. Hui, MD, ${ }^{a}$ and Richard Lee, MD, MBA ${ }^{\mathrm{b}}$
}

From the a Department of Cardiothoracic Surgery, University of Texas Health Science Center at San Antonio, San Antonio, Tex; and ${ }^{\mathrm{b}}$ Division of Cardiothoracic Surgery, Department of Surgery, Medical College of Georgia, Augusta University, Augusta, Ga.

Disclosures: Authors have nothing to disclose with regard to commercial support.

Received for publication July 31, 2019; accepted for publication Aug 1, 2019; available ahead of print Nov 4, 2019.

Address for reprints: Richard Lee, MD, MBA, Department of Surgery, Medical College of Georgia, 1120 15th St, BA-4300, Augusta, GA 30912 (E-mail: richardleemdmba@gmail.com; RICKLEE@augusta.edu).

J Thorac Cardiovasc Surg 2020;159:1428-9

$0022-5223 / \$ 36.00$

Copyright (c 2019 by The American Association for Thoracic Surgery

https://doi.org/10.1016/j.jtcvs.2019.08.014

In this edition of the Journal, Filardo and colleagues ${ }^{1}$ provide an update on their previous study ${ }^{2}$ of postoperative atrial fibrillation (POAF) after isolated coronary artery bypass grafting. Their previous study suggested that there are epidemiologic differences in the incidence of POAF between women and men. ${ }^{2}$ Their current study ${ }^{1}$ is intriguing both for what it reveals and what it does not. In riskadjusted analysis, POAF was less frequent and shorter in duration in women than in men. Despite these differences, its negative effect on survival was similar, with a greater than $50 \%$ increase in long-term mortality risk for both sexes relative to those without POAF.

Some comments regarding risk adjustment and risk prediction are warranted. In the original study, a propensityadjusted generalized estimating equations model approach was used. The variables used to estimate the propensity score will be familiar to all who use the Society of Thoracic Surgeons risk calculator. They are factors commonly used for mortality and morbidity prediction. "Risk-adjustment" should account for variables known or suspected to be associated with the outcome of interest, however, in this case POAF rather than mortality. At the current time, our knowledge is limited regarding which risk factors and of what magnitude for POAF, as evidenced by scant guidelines regarding who most benefits from POAF prophylaxis, as well as ongoing debates regarding the safety and efficacy of preoperative $\beta$-blockade. ${ }^{3}$ In fact, this very same author group examined risk prediction for atrial fibrillation at the same institutions during a similar time period, finding that the only score more predictive of POAF than age was the Cohorts for Heart and Aging Research in Genomic Epidemiology [CHARGE]-AF. ${ }^{4}$ Notably, the receiver operating characteristic area for CHARGE-AF was only 0.68 , landing it in the "poor test" category. ${ }^{5}$ The POAF, $\mathrm{CHA}_{2} \mathrm{DS}_{2}$ VASc, and Society of Thoracic Surgeons risk of mortality scores fared worse, with receiver operating characteristic areas of $0.65,0.59$, and 0.58 . Another recent study found higher C-statistics of 0.70 to 0.77 for the POAF,

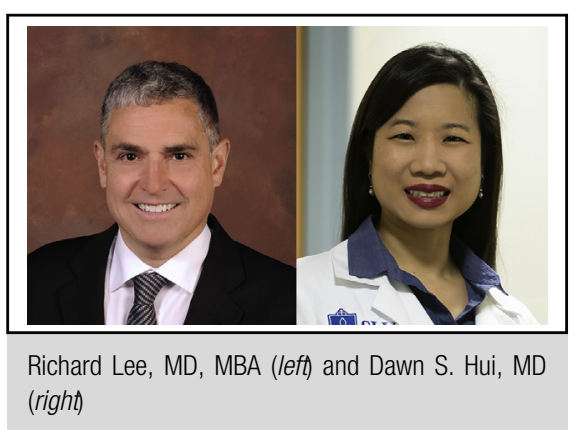

Central Message

A study on sex differences in postoperative atrial fibrillation highlights the opportunities to improve research and understanding generally of postoperative atrial fibrillation.

See Article page 1419.

$\mathrm{CHA}_{2} \mathrm{DS}_{2}$-VASc, and HATCH (hypertension [1 point], age $>75$ years [2 points], chronic obstructive pulmonary disease [ 1 point], and heart failure [2 points]) scores, but this was in a mixed population of cardiac surgeries, including valvular operations, which are known to have different POAF risk than isolated coronary artery bypass grafting. ${ }^{6}$ The list of factors for POAF remains to be defined, but it is likely not to be found completely within existing risk scores. Some known factors, such as left atrial dimension or $\mathrm{p}$-wave duration, ${ }^{7}$ are rarely included in databases.

A second important aspect of the study was linkage to the Social Security Death Master File (SSDMF). Society of Thoracic Surgeons leaders have made great strides in exploring the potential transformation of the Adult Cardiac Surgery Database into a tool for longitudinal follow-up through linkage to the Centers for Medicare and Medicare Services (CMS) Medicare database. ${ }^{8}$ In the study of Filardo and colleagues, ${ }^{1}$ the mean age in the study was younger than 65 years, so, a study that used CMS linkage would have excluded a fair number of the younger patients. Changes in death data reporting to the SSDMF since 2011 have affected accuracy of mortality determination, however, as predicted by Blackstone ${ }^{9}$ and confirmed in subsequent studies. $^{10,11}$ To account for this, the Filardo and colleagues ${ }^{1}$ censored survival data; however, the short interval of only 10 months between the surgical end-date and survival censor date certainly curtails the mortality analysis.

In short, the study of Filardo and colleagues ${ }^{1}$ prompts reflection on the ongoing need for investigation into the 
reasons for sex differences in POAF, better understanding and quantification of POAF risk factors, and greater appreciation for the long-term mortality risk that any POAF incurs.

\section{References}

1. Filardo G, Ailawadi G, Pollock BD, da Graca B, Phan TK, Thourain V, et al. Postoperative atrial fibrillation: sex-specific characteristics and effect on survival. $J$ Thorac Cardiovasc Surg. 2020;159:1419-25.e1.

2. Filardo G, Ailawadi G, Pollock BD, da Graca B, Sass DM, Phan TK, et al. Sex differences in the epidemiology of new-onset in-hospital post-coronary artery bypass graft surgery atrial fibrillation. Circ Cardiovasc Qual Outcomes. 2016; 9:723-30.

3. Hui DS, Lee R. Treatment of postoperative atrial fibrillation: the long road ahead. J Thorac Cardiovasc Surg. July 26, 2019 [Epub ahead of print].

4. Pollock BD, Filardo G, da Graca B, Phan TK, Ailawadi G, Thourani V, et al. Predicting new-onset post-coronary artery bypass graft atrial fibrillation with existing risk scores. Ann Thorac Surg. 2018;105:115-21.
5. Carter JV, Pan J, Rai SN, Galandiuk S. ROC-ing along: evaluation and interpretation of receiver operating characteristic curves. Surgery. 2016;159:1638-45.

6. Burgos LM, Seoane L, Parodi JB, Espinoza J, Galizia Brito V, Benzadón M, et al. Postoperative atrial fibrillation is associated with higher scores on predictive indices. J Thorac Cardiovasc Surg. 2019;157:2279-86.

7. Amar D, Shi W, Hogue CW Jr, Zhang H, Passman RS, Thomas T, et al. Clinical prediction rule for atrial fibrillation after coronary artery bypass grafting. J Am Coll Cardiol. 2004;44:1248-53.

8. Jacobs JP, Edwards FH, Shahian DM, Haan CK, Puskas JD, Morales DL, et al. Successful linking of the Society of Thoracic Surgeons adult cardiac surgery database to centers for Medicare and Medicaid Services Medicare data. Ann Thorac Surg. 2010;90:1150-6; discussion 1156-7.

9. Blackstone EH. Demise of a vital resource. J Thorac Cardiovasc Surg. 2012;143: 37-8.

10. Navar AM, Peterson ED, Steen DL, Wojdyla DM, Sanchez RJ, Khan I, et al Evaluation of mortality data from the social security administration death master file for clinical research. JAMA Cardiol. 2019;4:375-9.

11. Levin MA, Lin HM, Prabhakar G, McCormick PJ, Egorova NN. Alive or dead: validity of the social security administration death master file after 2011. Health Serv Res. 2019;54:24-33. Erratum in: Health Serv Res. 2019;54:722. 